\title{
Definitional dominance distributions for 20 English homographs
}

\author{
ROBERT E. WARREN, JAN H. BRESNICK, and JOHN P. GREEN \\ Columbia University, New York, New York 10027
}

\begin{abstract}
In order to establish the relative dominance of the various alternative meanings of 20 homographs, 100 subjects were given printed lists of words and asked to write a definition for each. Definitions were categorized and the frequency of definitions corresponding to each alternative meaning noted. Substantial variation in meaning dominance imbalance across homographs was observed. A high degree of correspondence between the dominance levels determined in this manner and those obtained by alternative methods was noted.
\end{abstract}

One of the persistent problems in the study of language comprehension is that of ambiguity. Quite aside from the ambiguity of entire conversations or paragraphs, individual words themselves often have more than one meaning. While it is generally agreed that word ambiguity is resolved through the consideration of context, the mechanisms governing the transition from a polysemous form to one embodying a single meaning are a matter of some dispute.

Hogaboam and Perfetti (1975) have suggested that when ambiguous words are encountered their meanings are accessed in order of their dominance. Dominance is said to correspond to the relative frequency of usage of the alternative meanings, the more common meaning being the most dominant. If one is to assess Hogaboam and Perfetti's hypothesis, it is first necessary to obtain dominance ratings of the alternative meanings of the words to be tested. Even if certain aspects of their ordered access hypothesis fail, it is apparent that dominance must reflect some basic difference in representations of the alternative forms of a word.

Recent studies which have attempted to resolve some of the problems in this area have typically employed homophones or homographs (Conrad, 1974; Warren \& Warren, 1976, Note 1) as prototypical examples of ambiguous words. A homophone is a phonemic form that has two distinct graphic representations corresponding to at least two distinct meanings, for example, $/ \mathrm{pI} \gamma /$ : peer-look, pier-dock. A homograph, on the other hand, is a graphic form that has two distinct phonemic representations corresponding to at least two meanings, for example, LEAD: /lid/ (guide), /led/ (metal).

While normative data from which meaning dominance can be inferred is readily available for homophones (Galbraith \& Taschman, 1969), norms for homographs

Requests for reprints should be sent to R. E. Warren, Department of Psychology, Columbia University, New York, New York 10027. The authors wish to thank N. T. Warren for her assistance in recruiting subjects. are not. Cramer (1970) has published free association norms to a few homographs and indicated for each the meaning related to the bulk of the associative responses. However, most of the stimulus words in her sample are ambiguous in both their graphic and phonemic forms (homonyms). A second source is the semantic frequency count done by Lorge and Thorndike (1938; Lorge, 1949). This count is based on a corpus of printed material gathered in the mid-1930s and is certainly the most extensive listing of meaning frequencies for polysemous words. Two factors limit its usefulness, however. First, while the 1938 count is usually available to researchers, the 1949 companion volume, in which the 570 most common English words are listed, is not so widely distributed. Second, homograph forms corresponding to the past tense of a verb (e.g., DOVE) are not listed separately but counted under the graphic form of the usual tense of the verb (e.g., DIVE). A third source (West, 1964) is derived from Lorge's work but lists only 2,000 words and excludes many less common meanings.

The present study attempts to determine meaning dominance for homographs by simply asking subjects to define them. The frequency with which a particular definition is given should reflect the underlying dominance of that meaning.

\section{METHOD}

\section{Subjects}

Fifty-three male and 47 female students at Columbia and Fordham Universities participated as part of a course requirement. Subjects were tested in groups.

\footnotetext{
Material and Procedure

Subjects were given a printed list of 20 homographs selected from Whitford's list (1966). Two random orders of the homographs were used and half the subjects received each order. Subjects were asked to write a definition for each word and then use the word in a sentence. They were informed that some (in fact, all) of the words might have more than one meaning and that they should write down the first definition that came to mind.
} 


\section{RESULTS AND DISCUSSION}

Only definitions were examined in establishing relative dominance of the alternative meanings of the homographs. Table 1 shows the homograph meanings and the number of subjects giving each definition. These values will total 100 unless errors (blanks or wrong definitions) were committed. Also included in Table 1 are dominance values obtained from Cramer (1970), Lorge (1949), and Lorge and Thorndike (1938). The Cramer values indicate the proportion of associative responses related to each meaning and the meaning to which the primary associative response was related. The Lorge values indicate the estimated frequency of each meaning per thousand occurrences of the word in written text.

A good degree of correspondence between the three methods of dominance assessment is apparent. Six homographs appear in both the present sample and in Cramer. In three cases (ENTRANCE, INCENSE, REFUSE) both the bulk of associative responses and the primary associate are related to the same meaning that appears dominant in the present study. In two additional cases (BASS, LEAD), one or the other of these indicators agrees with the present assessment.

Eighteen homographs appear in both Lorge and the present study. The two that do not (DOVE, WOUND) both have one form that is the past tense of a verb. Thirteen out of the 18 common homographs show the same pattern of dominance in both studies, while the homographs BASS, BOW, BUFFET, ROW, and TEAR do not.

The present results for BUFFET and REFUSE illustrate one disadvantage of the Lorge norms. In both cases one meaning which appears in the present results does not occur at all in the Lorge count. This may reflect shifts in usage over the 40-year period since the Lorge count was done or deficits in the actual corpus used. For the 16 remaining homographs evaluated both here and in the Lorge count, the correlation between dominant meaning frequencies was quite high $[\mathrm{r}=+.65$, $t(14)=2.96, p<.01]$.

Asking subjects to write definitions for ambiguous words appears to provide a good measure of relative meaning dominance. In cases where usage has shifted or where the graphic form corresponding to a verb tense is to be evaluated, it would seem to provide the most effective method for dominance assessment.

Table 1

Homograph Meanings and Dominance Levels

\begin{tabular}{|c|c|c|c|}
\hline Homograph & $\begin{array}{c}\text { Homograph } \\
\text { Definitions }\end{array}$ & $\begin{array}{l}\text { Columbia } \\
\text { Frequency }\end{array}$ & Cramer* Lorge $\dagger$ \\
\hline
\end{tabular}

\begin{tabular}{lllll}
\hline BASS & n. (or adj.) low-pitched & 57 & .580 & 334 \\
tone & n. fish & 43 & $.323 * *$ & 667
\end{tabular}

Table 1 Continued

\begin{tabular}{|c|c|c|c|c|}
\hline & $\begin{array}{c}\text { Homograph } \\
\text { Definitions }\end{array}$ & $\begin{array}{l}\text { Columbia } \\
\text { Frequency }\end{array}$ & Cramer* & Lorgef \\
\hline \multirow[t]{6}{*}{ BOW } & \multirow{6}{*}{$\begin{array}{l}\text { v. (or } n .) \text { to incline } \\
\text { body or head } \\
\text { n. a knot } \\
\text { n. a weapon } \\
\text { n. the prow of a ship } \\
\text { n. part of stringed } \\
\text { instrument } \\
\text { v. to yield }\end{array}$} & 57 & .306 & 243 \\
\hline & & 15 & & 12 \\
\hline & & 12 & $.460 * *$ & 359 \\
\hline & & 8 & & 83 \\
\hline & & 4 & & 13 \\
\hline & & 4 & & 51 \\
\hline \multirow[t]{3}{*}{ BUFFET } & n. informal meal & 82 & & \\
\hline & n. sideboard & 12 & & \\
\hline & v. (or n.) to strike & & & 1000 \\
\hline \multirow[t]{2}{*}{ CONVERSE } & v. to talk & 75 & & 641 \\
\hline & n. opposite & & & 128 \\
\hline \multirow[t]{2}{*}{ DESERT } & n. arid region & 69 & & 545 \\
\hline & v. to abandon & 26 & & 160 \\
\hline \multirow[t]{2}{*}{ DOVE } & n. bird & 92 & & \\
\hline & v. past of dive & 6 & & \\
\hline \multirow[t]{2}{*}{ ENTRANCE } & n. place of entry & 95 & $.873 * *$ & 875 \\
\hline & v. to put into a trance & 4 & .010 & 36 \\
\hline \multirow[t]{2}{*}{ INCENSE } & n. perfume from spices & 74 & $.880 * *$ & 458 \\
\hline & v. to anger & 25 & .086 & 417 \\
\hline \multirow[t]{2}{*}{ INVALID } & n. sick person & 73 & & 600 \\
\hline & adj. unfounded & 27 & & 67 \\
\hline \multirow[t]{3}{*}{ LEAD } & v. to direct, guide & 60 & $.470 * *$ & 758 \\
\hline & n. metal & 36 & .510 & 45 \\
\hline & n. vanguard & 4 & & 22 \\
\hline \multirow[t]{3}{*}{ LIVE } & v. to be alive, dwell, & & & \\
\hline & experience & 77 & & 656 \\
\hline & adj. alive, not dead & 22 & & 95 \\
\hline \multirow[t]{3}{*}{ LOWER } & v. to let down & 54 & & 342 \\
\hline & adj. below & 44 & & 636 \\
\hline & v. to frown, scowl & 0 & & 0 \\
\hline \multirow[t]{2}{*}{ MINUTE } & n. $1 / 60$ of an hour & 60 & & 815 \\
\hline & adj. tiny & 39 & & 182 \\
\hline \multirow[t]{4}{*}{ OBJECT } & n. thing & 43 & & 513 \\
\hline & v. to oppose & 41 & & 139 \\
\hline & n. end, goal & 12 & & 347 \\
\hline & n. part of speech & 4 & & 2 \\
\hline \multirow[t]{2}{*}{ REFUSE } & v. to reject, deny & 59 & $.716 * *$ & 1000 \\
\hline & n. trash & 41 & .180 & \\
\hline \multirow[t]{3}{*}{ ROW } & v. to propel with oar & 46 & & 228 \\
\hline & $\begin{array}{l}\text { n. a series in a con- } \\
\text { tinued line }\end{array}$ & 28 & & 632 \\
\hline & n. a quarrel & 26 & & 103 \\
\hline \multirow[t]{2}{*}{ SOW } & v. to scatter seed & 62 & & 634 \\
\hline & n. female swine & 33 & & 266 \\
\hline \multirow[t]{2}{*}{ TARRY } & v. to linger & 88 & & 910 \\
\hline & adj. tar covered & 2 & & 91 \\
\hline \multirow[t]{2}{*}{ TEAR } & v. (or n.) to rip & 69 & & 370 \\
\hline & n. droplet & 31 & & 601 \\
\hline \multirow[t]{3}{*}{ WOUND } & n. injury & 84 & & \\
\hline & v. to injure & 13 & & \\
\hline & v. past tense of wind & 3 & & \\
\hline
\end{tabular}

*Associative frequency

**Meaning to which primary associative response was related. fFrequency per 1000 


\section{REFERENCE NOTE}

1. Warren, R. E., \& Warren, N. T. Homophone meaning dominance and the dual encoding hypothesis. Paper presented at Psychonomic Society, St. Louis, 1976.

\section{REFERENCES}

Conrad, C. Context effects in sentence comprehension: A study of the subjective lexicon. Memory \& Cognition, 1974, 2, 130-138.

Cramer, P. A study of homographs. In L. Postman \& G. Keppel (Eds.), Norms of word association. Ne $\mathrm{v}$ York: Academic Press, 1970.

Galbraith, G. G., \& Taschman, C. S. Homophone units: A normative and methodological investigation of the strength of component elements. Journal of Verbal Learning and Verbal Behavior, 1969, 8, 737-744.

Hogaboam, T. W., \& Perfetti, C. A. Lexical ambiguity and sentence comprehension. Journal of Verbal Learning and Verbal Behavior, 1975, 14, 265-274.

LORGE, I. The semantic count of the 570 commonest English words. New York: Teachers College, Columbia University, 1949.

LORGE, I., \& ThORNDIKe, E. C. A semantic count of English words. New York: Teachers College, Columbia University, 1938.

WARrEN, R. E., \& W ARREN, N. T. Dual semantic encoding of homographs and homophones embedded in context. Memory \& Cognition, 1976, 4, 586-592.

WEST, M. P. A general service list of English words. London: Longmans, 1964.

WhITFORD, H. C. A dictionary of American homophones and homographs. New York: Teachers College, Columbia University, 1966.

(Received for publication May 31, 1977.) 